\title{
High Temperature Alters Sorbitol Metabolism in Pyrus pyrifolia Leaves and Fruit Flesh during Late Stages of Fruit Enlargement
}

\author{
Dongfeng Liu, Junbei Ni, Ruiyuan Wu, and Yuanwen Teng ${ }^{1}$ \\ Department of Horticulture, State Agriculture Ministry's Key Laboratory of Horticultural Plant \\ Growth, Development and Quality Improvement, Zhejiang University, 866 Yuhangtang Road, \\ Hangzhou, Zhejiang 310058, China
}

\begin{abstract}
Additional INDEX words. environmental stress, fruit development, fruit quality, pear, sorbitol accumulation, sorbitol transport, sugar composition

Abstract. Sorbitol is the main photosynthetic product and primary translocated carbohydrate in the Rosaceae and plays fundamental roles in plant growth, fruit quality, and osmotic stress adaptation. To investigate the effect of frequent high temperature during advanced fruit development on fruit quality of chinese sand pear [Pyrus pyrifolia (Burm. f.) Nakai], we analyzed sorbitol metabolism in mature leaves and fruit flesh of potted 'Wonhwang' pear trees. In mature leaves, sorbitol synthesis catalyzed by $\mathrm{NADP}^{+}$-dependent sorbitol-6-phosphate dehydrogenase (S6PDH) was repressed, while sorbitol utilization mainly catalyzed by $\mathrm{NAD}^{+}$-dependent sorbitol dehydrogenase $\left(\mathrm{NAD}^{+}\right.$-SDH) and $\mathrm{NADP}^{+}$-dependent sorbitol dehydrogenase $\left(\mathrm{NADP}^{+}-\mathrm{SDH}\right)$ was higher than that before high-temperature treatment, which resulted in decreased sorbitol accumulation. In contrast, sucrose accumulation in mature leaves was significantly enhanced in response to high temperatures. In fruit flesh, accumulation of sorbitol and sucrose was increased at the time of harvest under high temperatures. Among sorbitol metabolic enzymes, only NAD ${ }^{+}-S_{D H}$ was sensitive to high temperature in fruit flesh, and significant decrease of NAD ${ }^{+}$-SDH activity indicated that the fruit sorbitol-uptake capacity was undermined under high temperatures. Transcription analysis revealed tissue-specific responses of $\mathrm{NAD}^{+}-\mathrm{SDH}$ genes $(\mathrm{PpSDH} 1, \mathrm{PpSDH} 2$, and $\mathrm{PpSDH})$ to high-temperature treatment. The $\mathrm{NAD}^{+}-\mathrm{SDH}$ activity and regulation of $\mathrm{PpSDH1}$ and $\mathrm{PpSDH} 3$ were positively correlated in mature leaves. However, the downregulation of $P$ PSDH1 and $P$ PSDH2 was consistent with decreased enzyme activity in the fruit flesh. With regard to sorbitol transport, two sorbitol transporter genes (PpSOT1 and PpSOT2) were isolated, and downregulation of PPSOT2 expression in mature leaves indicated that the sorbitol-loading capability decreased under hightemperature conditions because of the limited sorbitol supply. These findings suggested that sorbitol metabolism responded differently in mature leaves and fruit flesh under high temperature, and that these dissimilar responses influenced fruit quality and may play important roles in adaptation to high temperatures.
\end{abstract}

Pear (Pyrus L.) is an important commercial fruit crop widely cultivated around the world. Since the 1980s, with the introduction and breeding of improved cultivars, the planting area of early-maturing chinese sand pear cultivars has gradually expanded in southern China. Pear production has become an important component of deciduous fruit production in this region. However, with global warming, the increasing frequency and duration of extreme high temperature in summer have negatively impacted the pear production (Wang et al., 2011). High temperature affects the external appearance of pear fruit and causes, for example, poor color development and increasing incidence of sunburn (Steyn et al., 2004; Wand et al., 2008). With these problems in mind, protective measures have been attempted with regard to field management or postharvest treatments (Colavita et al., 2011; Zhang et al., 2012). However, the effect of high temperatures on the internal quality of pear fruit is rarely studied.

Sugar metabolism is a basic biochemical process that affects internal fruit qualities, as sugar is the main taste component and is also a substrate for the biosynthesis of pigments, amino acids,

Received for publication 3 July 2013. Accepted for publication 27 Aug. 2013. We thank Deli Sun for help in tending the pear trees outdoors and the earmarked fund for Modern Agro-industry Technology Research System (nycytx-29) for financial support.

${ }^{1}$ Corresponding author. E-mail: ywteng@zju.edu.cn. vitamins, and aromatic volatiles. In Rosaceae fruit trees, sorbitol is the main product of photosynthesis and the form of carbohydrate transported in the phloem, and is also an important accumulated sugar alcohol in fruit (Loescher, 1987; Loescher et al., 1982). In pear, sorbitol content in mature leaves is nearly 4-fold higher than sucrose content (Colaric et al., 2006), whereas in fruit flesh it varies among species and fruit developmental stages. In chinese sand pear, sorbitol is the main sugar present during early fruit development and is almost equal in concentration to sucrose content at fruit maturity (Chen et al., 2011; Yao et al., 2010). Sorbitol metabolism in Rosaceae fruit also changes with fruit development and is related to fruit growth rate and sink strength (Bianco et al., 1999; Yamaki, 1986). Activity of $\mathrm{NAD}^{+}$-dependent sorbitol dehydrogenase $\left(\mathrm{NAD}^{+}-\mathrm{SDH}\right)$ is positively correlated with sink strength throughout peach (Prunus persica L.) fruit development, whereas sorbitol oxidase (SOX) activity is not correlated with sink strength at the endocarp hardening stage (Bianco and Rieger, 2002b). Therefore, the changes of sorbitol metabolism at specific fruit developmental stages are hypothesized to influence sink strength and fruit quality.

Pome fruit undergo three main growth periods during development: an initial period of cell division, a period of rapid enlargement owing to cell expansion, and final maturation. Sorbitol metabolism plays important roles in early fruit development and advanced fruit ripening (Nosarszewski et al., 
2004; Park et al., 2002). The few previous studies of sorbitol metabolism have focused specifically on the rapid fruit enlargement stage. This stage is a pivotal phase for the accumulation of organics in fruit and frequently coincides with a period of high temperature in early-maturing pear cultivars (Hai and Gao, 2010). High-temperature treatment before fruit maturity influences fruit ripening, color development, and the softening processes (Lurie et al., 1996), and disorders during fruit storage are probably related to environmental conditions experienced at the earlier developmental stages (Elgar et al., 1999; Neilsen et al., 2005). Therefore, investigation of sorbitol metabolic changes under high temperatures during fruit enlargement is important to improve fruit quality and storage life.

Sorbitol metabolism is influenced by environmental conditions. Under drought stress, both sorbitol synthesis in source leaves and its utilization in sink shoot tips are inhibited, and the sorbitol is accumulated up to $80 \%$ of total solutes for osmotic adjustment (Lo Bianco et al., 2000). Under moderate water stress, sorbitol metabolism in peach fruit is activated, and the concentrations of sorbitol and total sugars increase (Kobashi et al., 2000). Sorbitol transport is also affected by environmental conditions. Under osmotic stress, mRNA levels of sorbitol transporters are rapidly upregulated in vegetative tissues $(\mathrm{Li}$ et al., 2012; Pommerrenig et al., 2007). In this study, we investigated sorbitol transport and accumulation patterns as well as the activity and the expression level of sorbitol metabolic enzymes in mature leaves and fruit flesh to understand the fruit quality change under high-temperature treatment and the possible roles of sorbitol against the high-temperature stress.

\section{Materials and Methods}

Plant materials and treatments. Three-year-old P. pyrifolia cv. Wonhwang fruit-bearing trees on Pyrus calleryana Dcne. rootstock were planted in 53-L pots and tended in accordance with standard fertilization and pest-control practices outdoors. On 10 July 2012, 12 trees were transferred to an artificial climate chamber for adaptation at $27{ }^{\circ} \mathrm{C}$ for $3 \mathrm{~d}$. For high-temperature treatment, six trees were cultivated at $40{ }^{\circ} \mathrm{C}$ from 1200 to $1500 \mathrm{HR}$ and at $27^{\circ} \mathrm{C}$ for the remainder of the day (Fig. 1A), which simulated natural heat stress. Six trees were cultivated under a constant temperature of $27^{\circ} \mathrm{C}$ (the control). A completely randomized design with three replications and two trees per replicate were used in this experiment. All plants of the high-temperature treatment and the control were grown under conditions of 12-h illumination at $600 \mu \mathrm{mol} \cdot \mathrm{s}^{-1} \cdot \mathrm{m}^{-2}$ and $60 \%$ to $70 \%$ relative air humidity, and the trees were watered once daily to ensure adequate water supply. Daily high-temperature treatment was ended after $14 \mathrm{~d}$ because of the appearance of visible symptoms of damage to the leaves, after which the trees were cultivated under the same temperature as the control. Leaf and fruit samples were sampled weekly on four dates until fruit harvest (Fig. 1B). Five mature functional leaves and four fruit for each replication were sampled at $1500 \mathrm{HR}$, frozen in liquid $\mathrm{N}_{2}$, and stored at $-80{ }^{\circ} \mathrm{C}$ for analysis of enzyme activity and gene expression.

NET PHOTOSYNTHETIC RATE OF MATURE LEAVES UNDER HIGHTEMPERATURE TREATMENT. We measured the net photosynthetic rate $\left(\mathrm{P}_{\mathrm{n}}\right)$ twice daily on the sampling dates during the treatment period (13, 20, and 27 July) with a photosynthesis system (LI6400; LI-COR, Lincoln, NE). The measurements began at 1000 and $1400 \mathrm{HR}$, which represented $2 \mathrm{~h}$ before and $2 \mathrm{~h}$ after the start

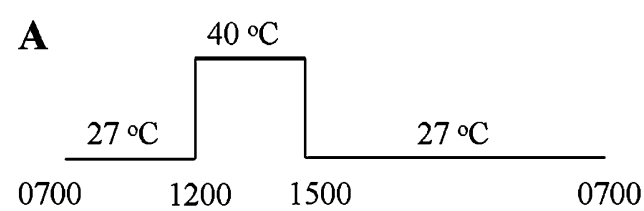

Time (HR)

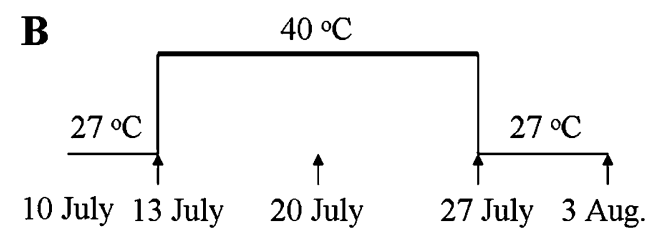

Date

Fig. 1. Temperature schedule for high-temperature treatment during late stage of fruit enlargement in Pyrus pyrifolia 'Wonhwang'. (A) Daily high temperature $\left(40{ }^{\circ} \mathrm{C}\right)$ from 1200 to $1500 \mathrm{HR}$ for high-temperature treatment. (B) Duration of daily high-temperature treatment from 13 to 27 July and recovery under control temperature $\left(27^{\circ} \mathrm{C}\right)$ until harvest on 3 Aug. Arrows indicate sampling dates.

of high-temperature treatment, respectively. The measurement parameters were $800 \mu \mathrm{mol} \cdot \mathrm{m}^{-2} \cdot \mathrm{s}^{-1}$ light intensity and 400 $\mu \mathrm{mol} \cdot \mathrm{mol}^{-1} \mathrm{CO}_{2}$.

SUgar CONTENT IN MATURE LEAVES AND FRUIT FLESH UNDER HIGH-TEMPERATURE TREATMENT. Sugar content was determined by high-performance liquid chromatography (Shimadzu, Kyoto, Japan). Soluble sugars in the fruit flesh were extracted in accordance with the method described by Huang et al. (2009). The method for sugar extraction from leaves was slightly modified. Ground leaf tissue $(0.2 \mathrm{~g})$ was homogenized in $6 \mathrm{~mL}$ distilled water and centrifuged at $5400 g_{\mathrm{n}}$ for $10 \mathrm{~min}$. One milliliter of supernatant was taken for filter sterilization and $10 \mu \mathrm{L}$ filtrate was injected into an $\mathrm{NH}_{2}$ column $(5.0 \mu \mathrm{m}, 4.6 \times$ $250 \mathrm{~mm}$; Sipore, Dalian, China) and detected with a refractive index detector (RID-10A; Shimadzu). Standard curves for fructose, glucose, sorbitol, and sucrose (Sigma, St Louis, MO) were generated as references to quantify sugar content in the samples.

SORBITOL METABOLIC ENZYME ACTIVITIES IN MATURE LEAVES AND FRUIT FLESH. Crude enzymes were extracted from $0.2 \mathrm{~g}$ leaves or $1.5 \mathrm{~g}$ fruit flesh in $5 \mathrm{~mL}$ Tris-HCl buffer $(100 \mathrm{~mm}, \mathrm{pH}$ 9.0) containing glycerol $(8 \%, \mathrm{v} / \mathrm{v})$, Tween $20(0.1 \%$, v/v), polyvinylpolypyrrolidone $(1 \%, \mathrm{w} / \mathrm{v})$, and 2 -mercaptoethanol $(20 \mathrm{~mm})$, and the activities of S6PDH (reduction of G6P activity), $\mathrm{NAD}^{+}-\mathrm{SDH}$, and $\mathrm{NADP}^{+}-\mathrm{SDH}$ were assayed by measuring the absorbance of nicotinamide adenine dinucleotide phosphate (NADPH) or nicotinamide adenine dinucleotide (NADH) at $340 \mathrm{~nm}$, and the activity of SOX was determined by measuring the absorbance of reducing sugar at $540 \mathrm{~nm}$ (Bianco et al., 1998, 1999; Kanayama and Yamaki, 1993).

Gene Cloning and Quantitative Real-time PCR. Total RNA was extracted from fruit flesh. Digested RNA treated with DNase I was reverse transcribed using the Revert Aid First Strand cDNA Synthesis Kit (Fermentas, Ottawa, ON, Canada). The primers used to clone S6PDH, NAD ${ }^{+}-\mathrm{SDH}$, and SOT genes are listed in Table 1.

The primers used for quantitative real-time polymerase chain reaction [RT-qPCR (Table 1)] were designed on the basis of the $3^{\prime}$-untranslated region sequence. The primer 
Table 1. Primers used for cloning and quantification of $\mathrm{NADP}^{+}$-dependent sorbitol-6-phosphate dehydrogenase (S6PDH), NAD ${ }^{+}$-dependent sorbitol dehydrogenase (NAD $\left.{ }^{+}-\mathrm{SDH}\right)$, and sorbitol transporter (SOT) genes in Pyrus pyrifolia 'Wonhwang'.

\begin{tabular}{|c|c|c|c|c|}
\hline Gene & Forward primer $\left(5^{\prime}-3^{\prime}\right)$ & Reverse primer $\left(5^{\prime}-3^{\prime}\right)$ & $\begin{array}{l}\text { Product } \\
\text { length }(\mathrm{bp})\end{array}$ & $\begin{array}{l}\text { Annealing } \\
\text { temp }\left({ }^{\circ} \mathrm{C}\right)\end{array}$ \\
\hline \multicolumn{5}{|c|}{ Primers for gene cloning } \\
\hline PpS6PDH & AGAAACAGAAACAGCCTG & AAGCTCAGTTTATTGTAAGTAA & 1097 & 50.7 \\
\hline PpSDH1 & AAGAAGGGAGCTTACCTAAC & AGTCTCGCCTCTACTAGAAAT & 1188 & 51.3 \\
\hline PpSDH2 & TTTGGAGGAGAAGAAGTTTGTG & AATGGAACGTGCTTATTGTGA & 1352 & 54.4 \\
\hline PpSDH3 & GGCAAGGGAGGCCAATCCT & GGCGGAAAAATGATTTATATTGAAG & 1384 & 55.7 \\
\hline PpSOT1 & CTTGCACAGCCACTGGTATT & GGAGCAGAGTAAGAGGAGGAAC & 1884 & 54.4 \\
\hline PpSOT2 & CTTTCGCTTGTGCTATTCTG & AGTAACCTGTTCCGCTGTCT & 1654 & 54.0 \\
\hline \multicolumn{5}{|c|}{ Primers for quantification } \\
\hline PpS6PDH & CAACAAACCTGGGAGGGCATG & GAGGGGTGTGAGCTGTGGGAA & 217 & 59.3 \\
\hline PpSDH1 & AGTTTAACCTTTTGGCCGGTCCCTTT & $\begin{array}{l}\text { CGCCTCTACTAGAAATGTGA } \\
\text { TACCAAATGC }\end{array}$ & 151 & 62.3 \\
\hline PpSDH2 & CCTCACCCCTGCTGCTGCTA & CCCGCCCTCTACATTCTACG & 266 & 59.8 \\
\hline PpSDH3 & ATTTCGGATTCATCGAGAGGACAGGT & TGTGGTGCATGCCGAGATCTAATACA & 155 & 63.0 \\
\hline PpSOT1 & $\begin{array}{l}\text { GGGCAAGTTAATTAGATTA } \\
\text { GTGAGTGAATG }\end{array}$ & GGAGGAACATACTTTTATCGTGCGTGT & 127 & 58.3 \\
\hline PpSOT2 & GGACAACAGGGTGAACCTCTTAGCTT & GCTGTCTCCATACCAATGAACCTCCA & 167 & 60.9 \\
\hline
\end{tabular}

specificity for RT-qPCR was confirmed by obtaining a single melting-curve peak and a single band by agarose gel electrophoresis of the PCR products. The total reaction volume for each RT-qPCR was $15 \mu \mathrm{L}$, which comprised 7.5 $\mu \mathrm{L}$ SYBR Green PCR Supermix (Takara, Tokyo, Japan), $0.5 \mu \mathrm{L}$ per each primer, $1 \mu \mathrm{L}$ of $1: 10$ diluted cDNA, and $5.5 \mu \mathrm{L}$ double-distilled water. The amplification procedure comprised denaturation for $5 \mathrm{~min}$ at $94{ }^{\circ} \mathrm{C}, 45$ cycles of $94{ }^{\circ} \mathrm{C}$ for $10 \mathrm{~s}$, and $60{ }^{\circ} \mathrm{C}$ for $30 \mathrm{~s}$ on a LightCycler 480 (Roche, Basel, Switzerland). PpActin (JN684184) was used as a housekeeping gene (Yu et al., 2012). Relative gene expression levels were calculated with the $2^{-\Delta \Delta C T}$ method (Livak and Schmittgen, 2001).

Statistical anAlysis. Statistical analysis was performed using the least significant difference test at the 5\% significance level with SPSS software (version 13.0; IBM Corp., Armonk, NY).

\section{Results}

Net Photosynthetic RAte of MAture Leaves. On each measurement date, $P_{n}$ measured at 1400 HR (after 2 h of hightemperature treatment) was significantly lower compared with the control (Fig. 2). On the initial and middle sampling dates (13 and 20 July), $P_{n}$ measured at $1000 \mathrm{HR}$ (before the beginning of high-temperature treatment) was not significantly different to that of the control. However, with increasing duration of high-temperature treatment, $P_{n}$ measured on 27 July at $1000 \mathrm{HR}$ was $47.2 \%$ lower than that of the control (Fig. 2).

Different Sugar aCCUMUlation PATterns in MATURE LEAVES AND FRUIT FLESH UNDER HIGH-TEMPERATURE TREATMENT. Fructose and glucose contents in both mature leaves and fruit flesh showed no response to high temperature (data not shown). Nonetheless, different patterns of sorbitol and sucrose accumulation were observed in mature leaves and fruit flesh under high temperature. Sorbitol, the most abundant sugar in mature leaves, was significantly decreased under hightemperature treatment (Fig. 3A), and its proportion decreased from $51.2 \%$ to $58.1 \%$ in control leaves to $37.8 \%$ to $48.4 \%$ in treated leaves (Fig. 3B). However, the decrease in sorbitol content was partially compensated by sucrose accumulation, as the proportion of sucrose increased from $12.2 \%$ to $13.4 \%$ in control leaves to $17.9 \%$ to $22.3 \%$ in treated leaves (Fig. 3B). In fruit flesh, sorbitol accumulation was stable under high temperature except for a significant increase at harvest time (Fig. 3A). In contrast, sucrose content was significantly increased by high temperature since 27 July; at harvest, sucrose content in treated fruit flesh rose by $11.8 \%$ compared with that in control flesh (Fig. 3B).

ACTIVITY AND GENE EXPRESSION OF SORbitol METABoliC ENZYMES IN MATURE LEAVES. Responses among sorbitol metabolic enzymes to high-temperature treatment differed in mature leaves. The activity of S6PDH tended to decrease with increasing time and by high-temperature treatment. The difference of S6PDH between treatment and control reached a significant level on 20 July (Fig. 4A). Activity of NAD ${ }^{+}-\mathrm{SDH}$ in control leaves remained stable throughout the experimental period. High temperature significantly enhanced leaf NAD ${ }^{+}-\mathrm{SDH}$ activity, which had increased by $55.7 \%$ on 20 July and $40.6 \%$ on 27 July in treated leaves (Fig. 4A). Activity of NADP ${ }^{+}-\mathrm{SDH}$ in control leaves fluctuated during the experimental period and peaked on 3 Aug., similarly, it was fluctuated in treated leaves and significantly raised by $11.8 \%$ on 27 July by high-temperature treatment (Fig. 4A). Leaf SOX activity did not vary significantly with time or high temperature (Fig. 4A). Therefore, NAD ${ }^{+}-\mathrm{SDH}$ was more sensitive to high temperatures than $\mathrm{NADP}^{+}-\mathrm{SDH}$ and SOX in the sorbitol catabolism of mature leaves.

With regard to sorbitol metabolism, S6PDH and $\mathrm{NAD}^{+}-\mathrm{SDH}$ are the crucial enzymes for sorbitol biosynthesis and utilization, respectively. One S6PDH gene $[P p S 6 P D H$ (GenBank accession no. KC506733)] and three $\mathrm{NAD}^{+}-\mathrm{SDH}$ genes $[P p S D H 1$ (KC506730), PpSDH2 (KC506731), PpSDH3 (KC506732)] were isolated from the 'Wonhwang' fruit flesh. Expression of $P p S 6 P D H$ was inhibited under high temperatures, and significant downregulation was observed on 20 July (Fig. 5A). Expression of $P p S D H 1$ and $P p S D H 3$ was induced under high temperatures, and especially, the significant induction of $P p S D H 3$ on 20 and 27 July was corresponded to the increase of $\mathrm{NAD}^{+}-\mathrm{SDH}$ enzyme activity, whereas expression of PpSDH2 was unaffected under high temperatures (Fig. 5A). 


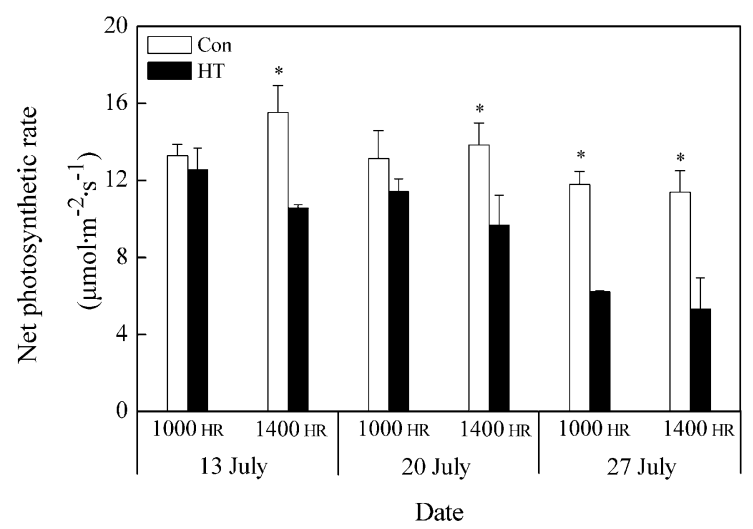

Fig. 2. Net photosynthesis rate $\left(\mathrm{P}_{\mathrm{n}}\right)$ of Pyrus pyrifolia 'Wonhwang' mature leaves in response to high-temperature treatment. $\mathrm{P}_{\mathrm{n}}$ was measured at 1000 and $1400 \mathrm{HR}$ on the sampling dates during the treatment period $(13,20$, and 27 July), which represented $2 \mathrm{~h}$ before and $2 \mathrm{~h}$ after the start of high-temperature treatment, respectively. The values represent the mean of three replications \pm SE. Asterisks indicate a significant difference between the control (Con) and high-temperature treatment $(\mathrm{HT})$ at $P<0.05$.

ACTIVITY AND GENE EXPRESSION OF SORBITOL METABOLIC ENZYMES IN FRUIT FLESH. Sorbitol metabolic enzymes in the fruit flesh were less sensitive to high temperature than those in mature leaves. Activities of S6PDH, NADP ${ }^{+}-\mathrm{SDH}$, and SOX were not significantly affected by high temperature (Fig. 4B). Changes of $\mathrm{NAD}^{+}-\mathrm{SDH}$ activity in fruit flesh were opposite to those observed in mature leaves, as $\mathrm{NAD}^{+}-\mathrm{SDH}$ activity in fruit flesh was inhibited under high temperature and with

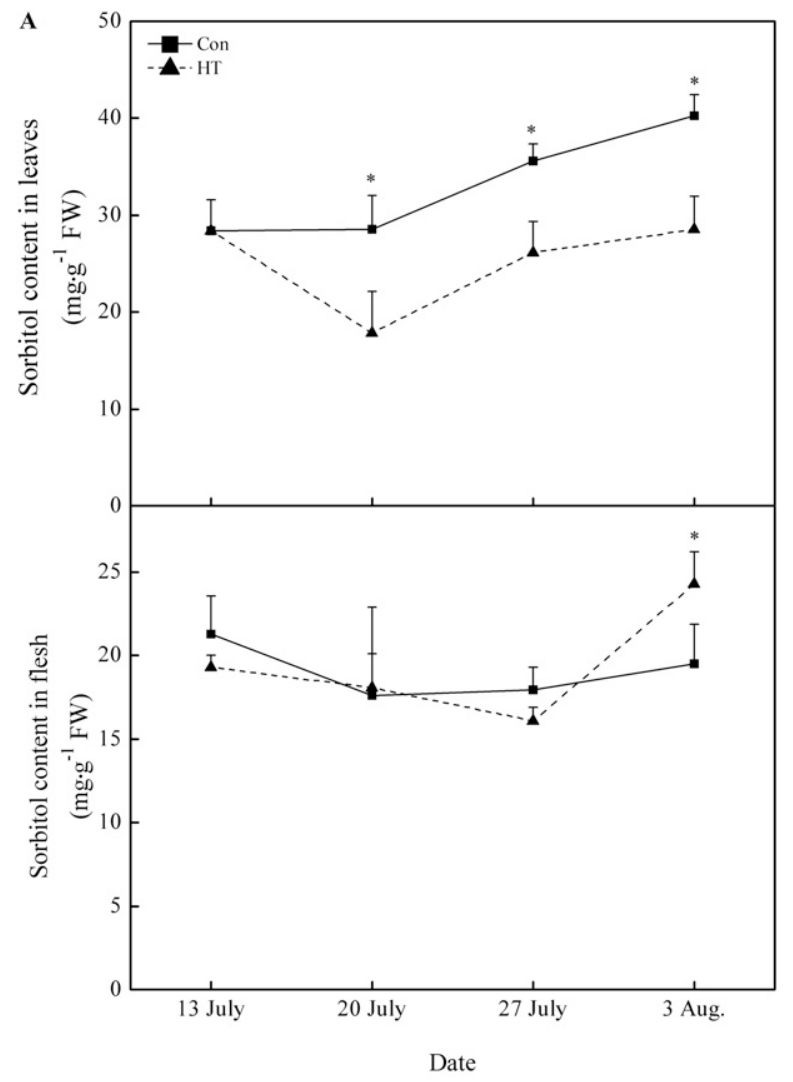

continued treatment was significantly decreased by $23.1 \%$ on 27 July (Fig. 4B).

The transcription pattern of S6PDH and $\mathrm{NAD}^{+}-\mathrm{SDH}$ genes in fruit flesh also differed from that observed in mature leaves. In sorbitol biosynthesis, expression of $P p S 6 P D H$ in fruit flesh was unaffected by high-temperature treatment (Fig. 5B). In sorbitol catabolism, expression of $P p S D H 1$ and $P p S D H 2$ was inhibited under high-temperature treatment, and significant downregulation was observed on 27 July, whereas expression of $P p S D H 3$ in fruit flesh was unaffected by high temperature (Fig. 5B).

TRANSCRIPTION OF SORBITOL TRANSPORTER GENES IN MATURE LEAVES AND FRUIT FLESH. Sorbitol transport is a carrier-mediated process in Rosaceae. Two SOT genes were isolated from 'Wonhwang' leaves and designated PpSOT1 (KC506734) and PpSOT2 (KC506735). PpSOT1 and PpSOT2 shared high sequence identity with MdSOT5 (AB125647.1) and MdSOT4 (AB125647.1), respectively, in apple (Malus $\times$ domestica Borkh). Expression of PpSOT1 and PpSOT2 was analyzed as an indicator of sorbitol transport capacity under high-temperature treatment. Expression of PPSOT1 was unaffected by high temperature in both mature leaves and fruit flesh, whereas PpSOT2 expression showed a tissue-specific response to high temperature. PpSOT2 was significantly downregulated in mature leaves but unaffected in fruit flesh under high-temperature treatment (Fig. 6). In addition, expression of SOT genes was regulated in tissue- and developmental stage-specific manner. With fruit development, expression of PpSOT2 in control leaves was significantly upregulated, whereas expression of PpSOT1 in fruit flesh was decreased (Fig. 6).

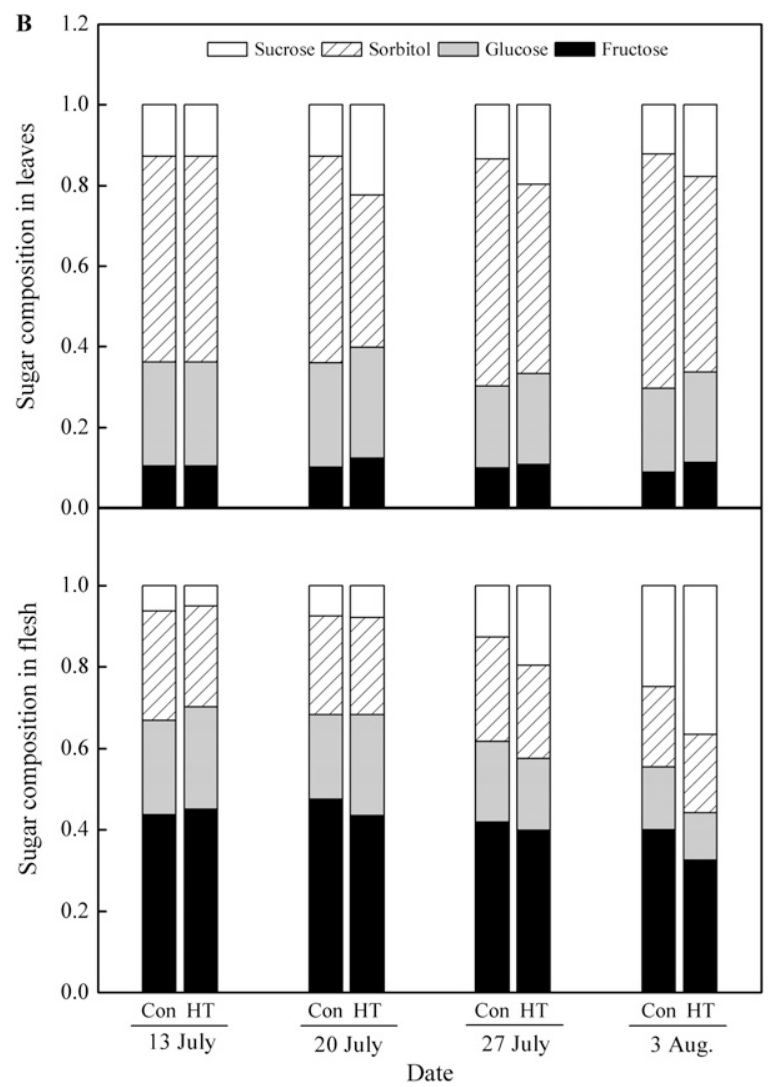

Fig. 3. (A) Sorbitol content and (B) sugar composition in Pyrus pyrifolia 'Wonhwang' mature leaves and fruit flesh in response to high-temperature treatment. The values represent the mean of three replications \pm SE. Asterisks indicate a significant difference between the control (Con) and high-temperature treatment (HT) at $P<0.05$. 
A

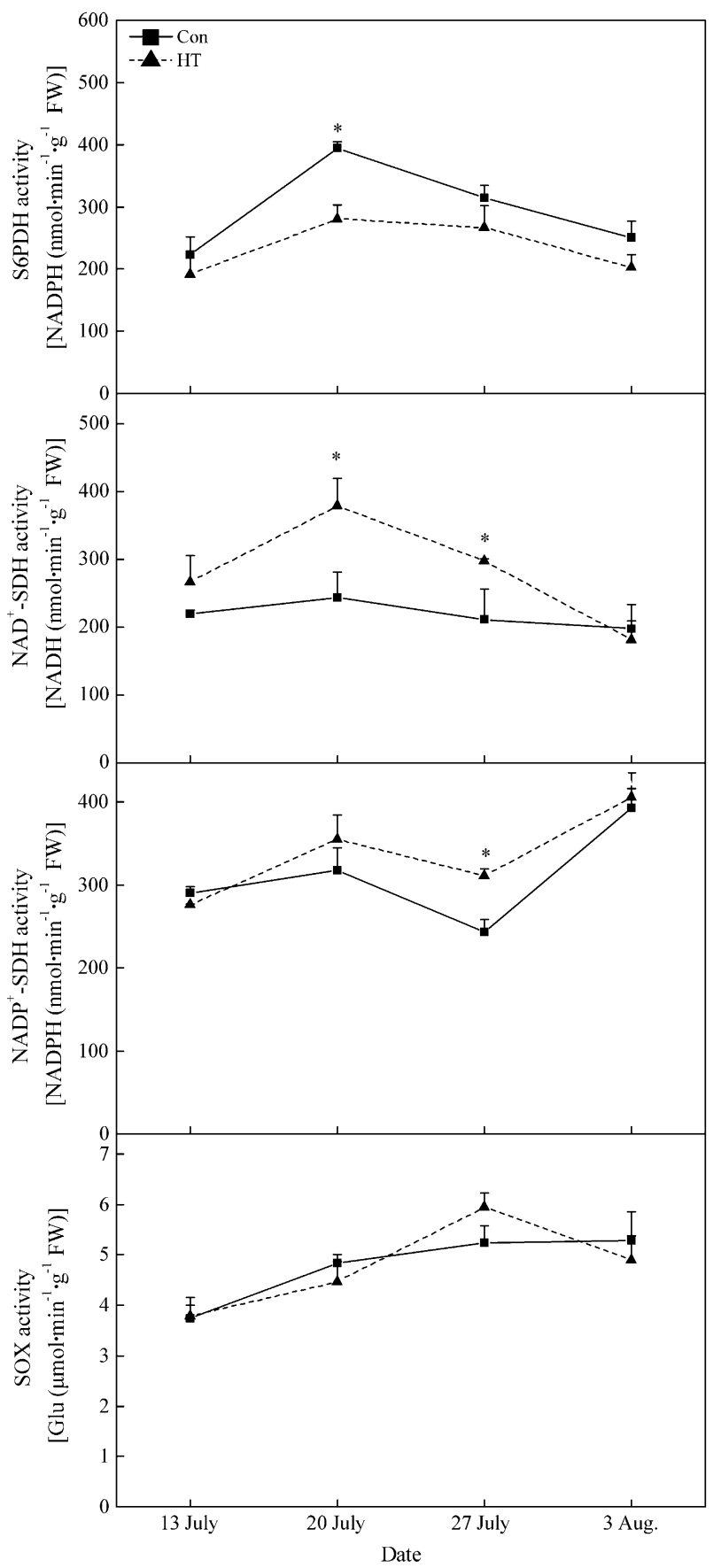

B

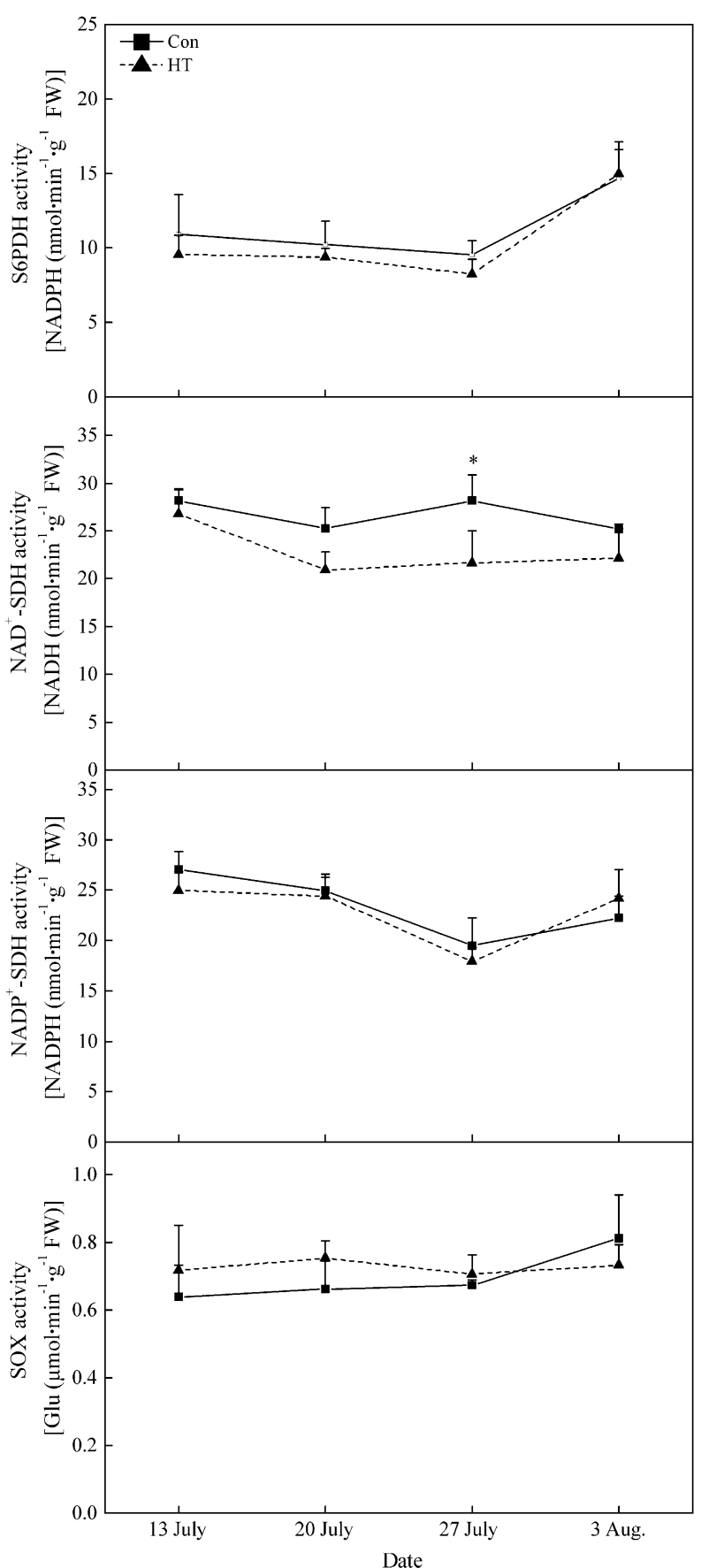

Fig. 4. Sorbitol metabolic enzyme activity in (A) Pyrus pyrifolia 'Wonhwang' mature leaves and (B) fruit flesh in response to high-temperature treatment; S6PDH = $\mathrm{NADP}^{+}$-dependent sorbitol-6-phosphate dehydrogenase, $\mathrm{NAD}^{+}-\mathrm{SDH}=\mathrm{NAD}^{+}$-dependent sorbitol dehydrogenase, $\mathrm{NADP}^{+}$-SDH $=\mathrm{NADP}^{+}$-dependent sorbitol dehydrogenase, $\mathrm{SOX}=$ sorbitol oxidase, $\mathrm{Glu}=$ glucose. The values represent the mean of three replications $\pm \mathrm{SE}$. Asterisks indicate a significant difference between the control (Con) and high-temperature treatment (HT) at $P<0.05$.

\section{Discussion}

SORbitol CONTENT, ACTIVITY, AND GENE EXPRESSION OF SORBITOL METABOLIC ENZYMES IN MATURE LEAVES UNDER HIGHTEMPERATURE TREATMENT. In the Rosaceae, sorbitol is a primary end product of photosynthesis and the principal translocated carbohydrate. Sorbitol biosynthesis in mature leaves influences sugar metabolism in fruit and fruit-quality attributes at maturity (Teo et al., 2006). In transgenic apple plants in which sorbitol synthesis is suppressed, besides alteration of sugar metabolism in leaves, the sugar and acid composition in fruit is changed, with higher glucose and lower fructose, starch, and malic acid concentrations accumulated (Teo et al., 2006). Furthermore, sorbitol metabolism is affected by environmental conditions. Under osmotic stress, sorbitol is accumulated and functions as a cell osmotic adjustment substance (Noiraud et al., 2001; Wang and Stutte, 1992). However, under high-temperature treatment, the sorbitol content decreased and sugar composition changed 
A

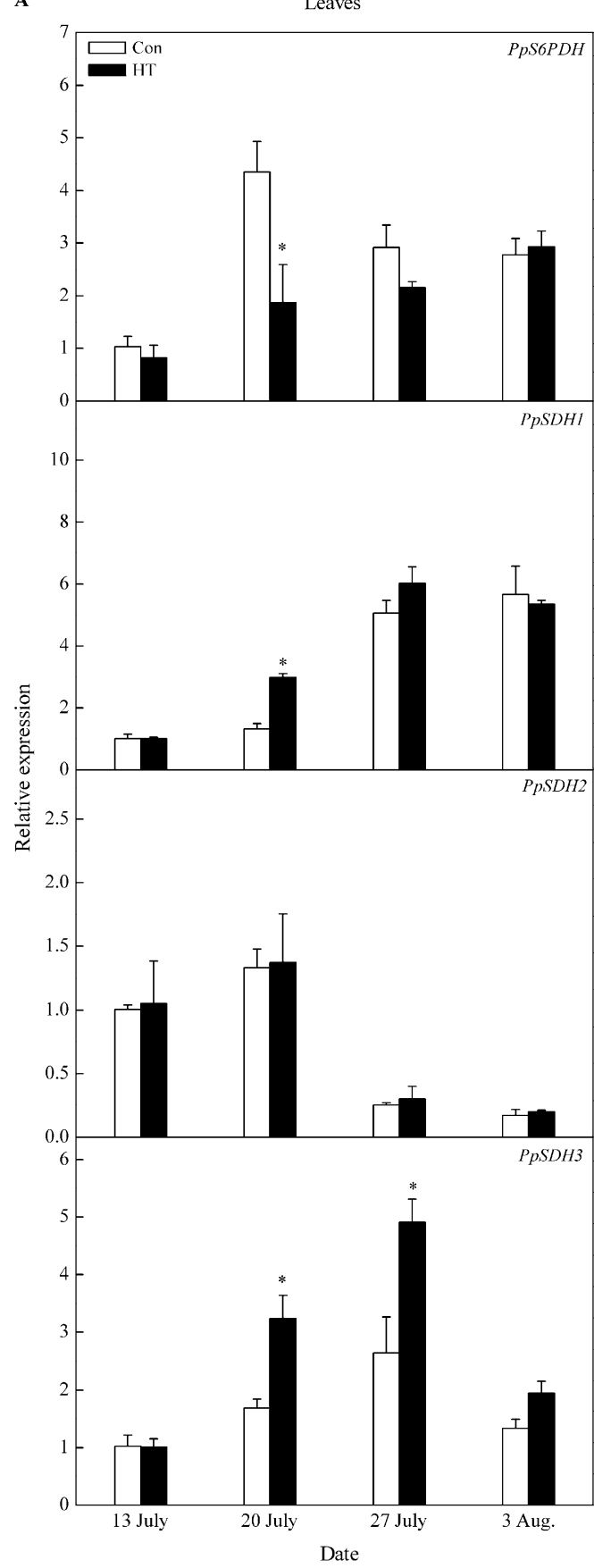

B

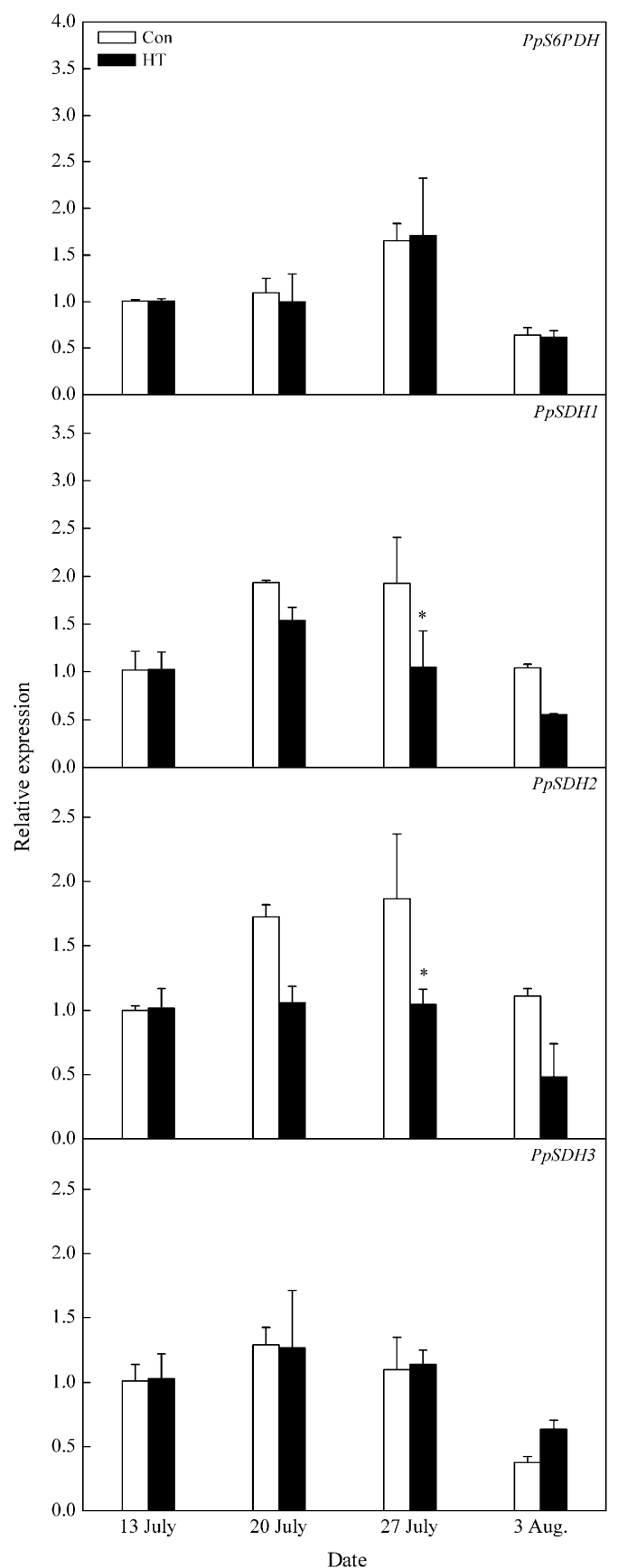

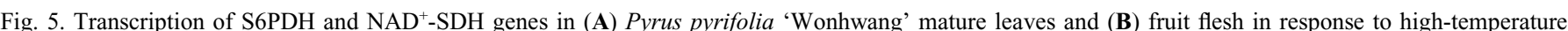
treatment; $P p S 6 P D H=$ NADP $^{+}$-dependent sorbitol-6-phosphate dehydrogenase gene, $P p S D H 1-3=\mathrm{NAD}^{+}$-dependent sorbitol dehydrogenase genes. The values represent the mean of three replications \pm SE. Asterisks indicate a significant difference between the control (Con) and high-temperature treatment $(\mathrm{HT})$ at $P<0.05$.

in mature leaves of pear. In control leaves, sorbitol accounted for the highest proportion of total sugars $(51.2 \%$ to $58.1 \%)$, which was consistent with the reports in apple and apricot (Prunus armeniaca L.) (Bieleski and Redgwell, 1985; Loescher et al., 1982), whereas the proportion significantly decreased to $37.8 \%$ to $48.4 \%$ in heat-stressed leaves (Fig. 3A). Analysis of enzyme activities indicated that the lower sorbitol accumulation in mature leaves was due to a combination of decreased sorbitol synthesis and enhanced sorbitol catabolism. S6PDH and $\mathrm{NAD}^{+}-\mathrm{SDH}$ are key enzymes for sorbitol synthesis and utilization, respectively (Yamaguchi et al., 1994; Yamaki, 1986). The activity and transcript level of S6PDH were decreased under high-temperature treatment (Fig. 4A and $5 \mathrm{~A}$ ), which was consistent with the inhibition of photosynthesis in mature leaves (Fig. 2). In contrast, $\mathrm{NAD}^{+}-\mathrm{SDH}$ activity was significantly increased under high-temperature treatment (Fig. $4 \mathrm{~A}$ ), and upregulation of $\mathrm{PpSDH} 1$ and $\mathrm{PpSDH} 3$ was consistent with increased enzyme activity in mature leaves (Fig. 5A). However, among sorbitol metabolic enzymes only $\mathrm{NAD}^{+}-\mathrm{SDH}$ activity was significantly correlated with sorbitol content 

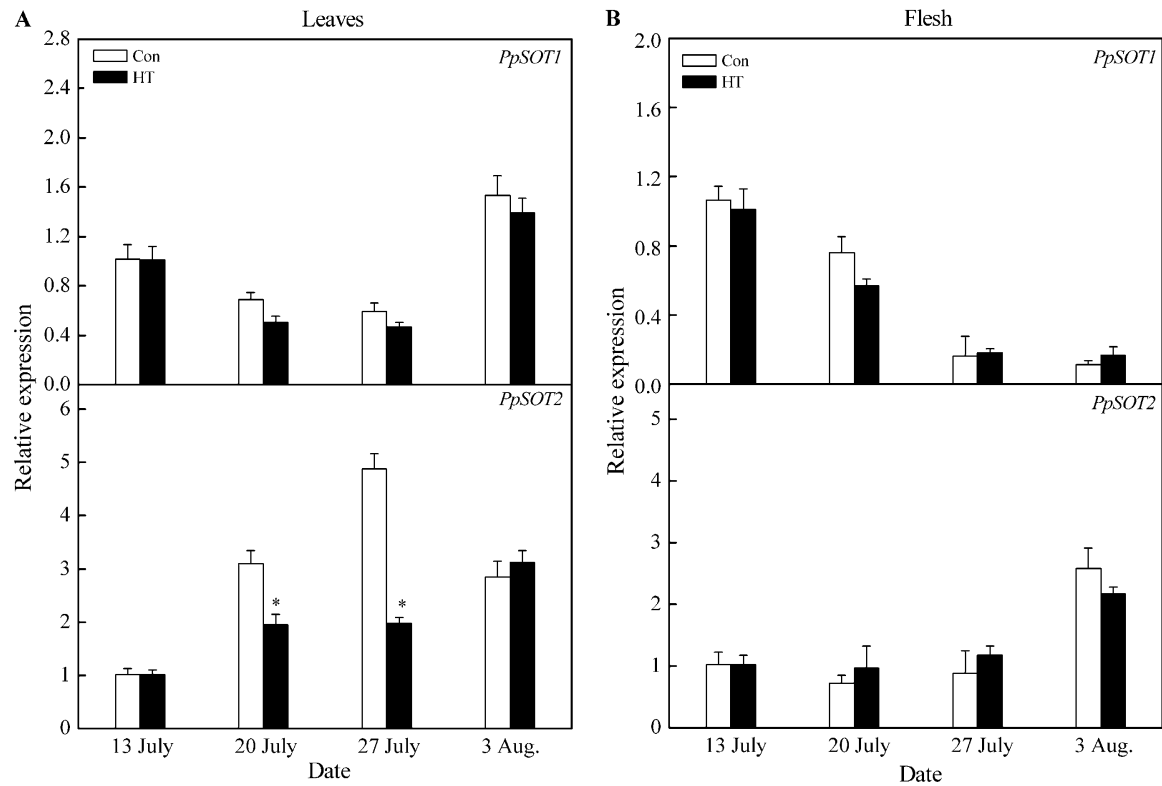

Fig. 6. Transcription of sorbitol transporter genes in (A) Pyrus pyrifolia 'Wonhwang' mature leaves and (B) fruit flesh in response to high-temperature treatment; PpSOT1-2 = sorbitol transporter genes. The values represent the mean of three replications \pm SE. Asterisks indicate a significant difference between the control (Con) and hightemperature treatment (HT) at $P<0.05$.

$(R=-0.800, P=0.017)$, which implied that the decreased sorbitol content in mature leaves mainly resulted from increased $\mathrm{NAD}^{+}-\mathrm{SDH}$ activity under high-temperature treatment. Moreover, the response of $\mathrm{NAD}^{+}$-SDH under high-temperature treatment conflicted with the reported responses to drought or salt stress (Lo Bianco et al., 2000; Nosarzewski et al., 2012; Pommerrenig et al., 2007; Ranney et al., 1991), which may be the main reason for low sorbitol accumulation in mature leaves under high temperatures.

Under the above-mentioned osmotic stress conditions, accumulation of sorbitol accompanies decreased $\mathrm{NAD}^{+}-\mathrm{SDH}$ activity. However, it is also reported that sorbitol accumulation is associated with upregulation of S6PDH or its homologue aldose reductase under osmotic stress (Deguchi et al., 2002; Kanayama et al., 2007; Tari et al., 2010). Regardless, sorbitol accumulation is beneficial for osmotic adaptation. However, under high-temperature treatment, sorbitol synthesis was weakened as a result of photosynthesis inhibition (Fig. 2), whereas sorbitol utilization tended to increase with upregulation of $\mathrm{NAD}^{+}$-SDH genes. Accordingly, sorbitol accumulation was decreased in mature leaves under high-temperature treatment. Therefore, sorbitol accumulation patterns could be dependent on stress conditions. Interestingly, the decrease of sorbitol content in mature leaves was compensated by sucrose accumulation under high-temperature treatment (Fig. 3B). The increase in sucrose content is associated with upregulation of sucrose synthase and sucrose phosphate synthase genes (data not published). The compensation of sorbitol by sucrose was also observed in S6PDH-suppressed transgenic apple plants, with sucrose content increased 3.7-fold when sorbitol accumulation decreased to $22 \%$ of the control in GSA04 apple (Teo et al., 2006; Zhou et al., 2006). Therefore, a relationship between sorbitol and sucrose metabolism under high temperatures is implied.

SORBITOL CONTENT, ACTIVITY, AND GENE EXPRESSION OF SORBITOL METABOLIC ENZYMES IN FRUIT FLESH UNDER HIGHTEMPERATURE TREATMENT. In most ripe Rosaceae fruit, sorbitol is not the predominant constituent sugar, despite it being the primary imported sugar, which indicates that sorbitol is rapidly metabolized in the fruit (Yamaki, 1986). Unloaded sorbitol in fruit is oxidized to fructose or glucose or is stored. The proportion of sorbitol in ripe Rosaceae fruit varies among species. Ripe apple and peach fruit contain little sorbitol, and fructose or sucrose, respectively, accounts for the maximum sugar ratio (Vizzotto et al., 1996; Yamaki, 1986). However, cherries (Prunus cerasus L. and Prunus avium L.) accumulate large amounts of sorbitol in mature fruit (Gao et al., 2003). In pear fruit, the sorbitol content is highly variable among cultivars. Sorbitol content in Pyrus communis L. is higher than that in Pyrus ussuriensis Maxim. (Yao et al., 2010). In P. pyrifolia cv. Wonhwang fruit, the proportion of fructose was highest and that of glucose lowest, and sorbitol proportion was equal to that of sucrose in the flesh of the control (Fig. 3B). Under high-temperature treatment, sorbitol content was maintained at a steady level except for a significant increase on 3 Aug., whereas sucrose was rapidly accumulated since 27 July (Fig. 3).

Among the sorbitol metabolic enzymes analyzed, only $\mathrm{NAD}^{+}-\mathrm{SDH}$ activity was significantly decreased in fruit flesh under high temperature; the other three enzymes analyzed were insensitive to high temperature (Fig. $4 \mathrm{~B}$ ). $\mathrm{NAD}^{+}-\mathrm{SDH}$ is a crucial enzyme in sorbitol catabolism and is ubiquitously distributed in a variety of plant tissues and organs (Wang et al., 2009; Wu et al., 2010). In fruit, $\mathrm{NAD}^{+}-\mathrm{SDH}$ activity varies with development stage (Bianco and Rieger, 2002a; Yamaki, 1986) and exhibits a high level of activity at fruit set and during fruit maturation (Nosarszewski et al., 2004; Park et al., 2002), which indicates that $\mathrm{NAD}^{+}-\mathrm{SDH}$ plays important roles in sink strength establishment and fruit ripening. In this study, $\mathrm{NAD}^{+}-\mathrm{SDH}$ activity in fruit flesh decreased in response to high-temperature stress, which indicated that sink strength of fruit was weakened and fruit enlargement may be affected under high temperature.

$\mathrm{PpSDH1}$ and $\mathrm{PpSDH} 2$ were downregulated under hightemperature treatment (Fig. 5B), which was consistent with the decrease of $\mathrm{NAD}^{+}$-SDH activity (Fig. 4B). However, increased $\mathrm{NAD}^{+}$-SDH activity in mature leaves was a result of upregulation of $\mathrm{PpSDH1}$ and $\mathrm{PpSDH} 3$ under high-temperature treatment (Fig. 5A); therefore, expression of $\mathrm{NAD}^{+}$-SDH genes was tissue-specific under high temperature. Tissue-specific expression of nine SDH genes in apple is also reported. Expression of $M d S D H 2, M d S D H 3$, and $M d S D H 4$ is restricted to sink organs such as young leaves, stems, roots, and maturing fruit, whereas $M d S D H 1$ is highly expressed in leaves (Park et al., 2002). In apple fruit, five of the nine SDH genes ( $\mathrm{SDH} 1, \mathrm{SDH} 2, \mathrm{SDH}$, $S D H 6$, and $S D H 9$ ) are expressed in fruit, but only $S D H 2$ is limited to the cortex, and $S D H 6$ and $S D H 9$ are expressed in the seed (Nosarzewski and Archbold, 2007). Fifteen SDH genes are reported in the pear genome, which is much more than in other 
rosaceous and nonrosacaeous species such as strawberry (Fragaria vesca L.) and papaya (Carica papaya L.), and the complex multigene family in pear might be related to the wholegenome duplication from nine chromosomes of the Rosaceae ancestor (Wu et al., 2013). Consequently, the whole-genome duplication may have been the origin of the large multigene family and promote the specific sorbitol metabolism pathway; however, it may also have led to complex expressional regulation and functional redundancy. Although the current information was insufficient to reveal the regulatory mechanism of sorbitol metabolism under high temperature, it demonstrated the tissue-specific response of $\mathrm{NAD}^{+}-\mathrm{SDH}$ genes to high temperature.

EXPRESSION OF SORBITOL TRANSPORTER GENES IN MATURE LEAVES AND FRUIT FLESH UNDER HIGH-TEMPERATURE TREATMENT. Sorbitol transporters are essential components that mediate cross-membrane transport of sorbitol, including its export from the source leaf, long-distance distribution in the phloem, and import into sink tissues. Sorbitol transporters have been identified in a variety of plants such as sour cherry $[P$. cerasus (Gao et al., 2003)], apple (Li et al., 2012; Watari et al., 2004), and plantain [Plantago major L. (Pommerrenig et al., 2007)]. In this study, two SOT genes (PpSOT1 and PpSOT2) were isolated of which only PpSOT2 in mature leaves was significantly downregulated under high temperature (Fig. 6A). Sugar transport is regulated by sugar availability and stress conditions (Roitsch, 1999); therefore, decreased sorbitol content in mature leaves could regulate expression of PpSOT2 under high-temperature treatment. Similar regulation is also reported in apple. Expression of MdSOT3 and MdSOT5 in leaves is upregulated with increase in sorbitol accumulation, whereas expression of MdSOT4 showed tissue-specific transcript patterns under drought stress (Li et al., 2012). Similarly, PpSOT2, which showed high sequence identity to MdSOT4, showed tissue-specific response to heat stress (Fig. 6). In addition, the sorbitol transporters play important roles in sink tissues. A defective SOT in apple fruit leads to abnormal sorbitol accumulation in the apoplast and the fruit watercore disorder (Gao et al., 2005). In this study, although expression of the two SOT genes in fruit flesh was unaffected by high temperature (Fig. 6B), the expression and function of other SOT genes should be verified because a much higher number of SOT genes is present in the pear genome than in other plant species, e.g., 35 in pear, 11 in strawberry, 12 in papaya, 8 in grape (Vitis vinifera L.), and 10 in tomato (Solanum lycopersicum L.) (Wu et al., 2013).

As a specific and important pathway in rosaceous species, sorbitol metabolism has been genetically modified to improve resistance to osmotic stresses and, furthermore, sorbitol accumulation as an osmoprotectant also changes fruit quality. The indentified genes involved in sorbitol metabolism responsive to high temperature could be exploited to improve pear fruit quality and thermotolerance under high-temperature growing conditions.

In this study, it was shown that with the transcriptional regulation of sorbitol metabolizing enzymes, depressed synthesis, and increased utilization led to low sorbitol accumulation in mature leaves after high-temperature treatment, whereas sorbitol metabolism in fruit flesh was less sensitive to that in mature leaves under high-temperature conditions. However, the significant accumulation of sucrose in fruit flesh indicated that fruit quality was influenced by high temperature during advanced fruit enlargement. In addition, from an environmental adaptation perspective, the responses of sorbitol metabolism and changes of sugar composition in mature leaves and fruit flesh could be beneficial for thermotolerance under high temperatures. Therefore, understanding the regulation of sorbitol metabolism under high temperature may be helpful to improve the stress resistance of rosaceous plants.

\section{Literature Cited}

Bianco, R.L. and M. Rieger. 2002a. Partitioning of sorbitol and sucrose catabolism within peach fruit. J. Amer. Soc. Hort. Sci. 127:115-121. Bianco, R.L. and M. Rieger. 2002b. Roles of sorbitol and sucrose in growth and respiration of 'Encore' peaches at the three developmental stages. J. Amer. Soc. Hort. Sci. 127:297-302.

Bianco, R.L., M. Rieger, and S.-J.S. Sung. 1998. A simple, rapid extraction and assay procedure for $\mathrm{NAD}^{+}$-dependent sorbitol dehydrogenase (SDH) in peach. J. Amer. Soc. Hort. Sci. 123:1065-1068. Bianco, R.L., M. Rieger, and S.-J.S. Sung. 1999. Activities of sucrose and sorbitol metabolizing enzymes in vegetative sinks of peach and correlation with sink growth rate. J. Amer. Soc. Hort. Sci. 124:381388.

Bieleski, R. and R. Redgwell. 1985. Sorbitol versus sucrose as photosynthesis and translocation products in developing apricot leaves. Funct. Plant Biol. 12:657-668.

Chen, L., T. Wang, X. Huang, C. Lu, D. Liu, X. Zheng, and Y. Teng. 2011. Study on enzyme activities involved in sugar accumulation and sucrose metabolization in Cuiguan pear under plastic tunnel culture. J. Fruit Sci. 28:400-405.

Colaric, M., F. Stampar, and M. Hudina. 2006. Changes in sugars and phenolics concentrations of Williams pear leaves during the growing season. Can. J. Plant Sci. 86:1203-1208.

Colavita, G.M., V. Blackhall, and S. Valdez. 2011. Effect of kaolin particle films on the temperature and solar injury of pear fruits. Acta Hort. 609-615.

Deguchi, M., M. Watanabe, and Y. Kanayama. 2002. Increase in sorbitol biosynthesis in stressed japanese pear leaves. Acta Hort. 511-517.

Elgar, H.J., N. Lallu, and C.B. Watkins. 1999. Harvest date and crop load effects on a carbon dioxide-related storage injury of 'Braeburn' apple. HortScience 34:305-309.

Gao, Z., S. Jayanty, R. Beaudry, and W. Loescher. 2005. Sorbitol transporter expression in apple sink tissues: Implications for fruit sugar accumulation and watercore development. J. Amer. Soc. Hort. Sci. 130:261-268.

Gao, Z., L. Maurousset, R. Lemoine, S.-D. Yoo, S. Van Nocker, and W. Loescher. 2003. Cloning, expression, and characterization of sorbitol transporters from developing sour cherry fruit and leaf sink tissues. Plant Physiol. 131:1566-1575.

Hai, Y. and Z. Gao. 2010. The analysis of temporal and spatial features of climate change in the last 100 years in China. Bul. Sci. Technol. 26:58-62.

Huang, C., B. Yu, Y. Teng, J. Su, Q. Shu, Z. Cheng, and L. Zeng. 2009. Effects of fruit bagging on coloring and related physiology, and qualities of red chinese sand pears during fruit maturation. Sci. Hort. 121:149-158.

Kanayama, Y., R. Moriguchi, M. Deguchi, K. Kanahama, and S. Yamaki. 2007. Effects of environmental stresses and abscisic acid on sorbitol-6-phosphate dehydrogenase expression in Rosaceae fruit trees. Acta Hort. 738:375-381.

Kanayama, Y. and S. Yamaki. 1993. Purification and properties of NADP-dependent sorbitol-6-phosphate dehydrogenase from apple seedlings. Plant Cell Physiol. 34:819-823.

Kobashi, K., H. Gemma, and S. Iwahori. 2000. Abscisic acid content and sugar metabolism of peaches grown under water stress. J. Amer. Soc. Hort. Sci. 125:425-428.

Li, F., H. Lei, X. Zhao, R. Tian, and T. Li. 2012. Characterization of three sorbitol transporter genes in micropropagated apple plants grown under drought stress. Plant Mol. Biol. Rpt. 30:123-130. 
Livak, K.J. and T.D. Schmittgen. 2001. Analysis of relative gene expression data using real-time quantitative PCR and the $2^{-\Delta \Delta C T}$ method. Methods 25:402-408.

Lo Bianco, R., M. Rieger, and S.-J.S. Sung. 2000. Effect of drought on sorbitol and sucrose metabolism in sinks and sources of peach. Physiol. Plant. 108:71-78.

Loescher, W.H. 1987. Physiology and metabolism of sugar alcohols in higher plants. Physiol. Plant. 70:553-557.

Loescher, W.H., G.C. Marlow, and R.A. Kennedy. 1982. Sorbitol metabolism and sink-source interconversions in developing apple leaves. Plant Physiol. 70:335-339.

Lurie, S., A. Handros, E. Fallik, and R. Shapira. 1996. Reversible inhibition of tomato fruit gene expression at high temperature (effects on tomato fruit ripening). Plant Physiol. 110:1207-1214.

Neilsen, G., D. Neilsen, S. Dong, P. Toivonen, and F. Peryea. 2005. Application of $\mathrm{CaCl}_{2}$ sprays earlier in the season may reduce bitter pit incidence in 'Braeburn' apple. HortScience 40:1850-1853.

Noiraud, N., L. Maurousset, and R. Lemoine. 2001. Transport of polyols in higher plants. Plant Physiol. Biochem. 39:717-728.

Nosarszewski, M., A.M. Clements, A.B. Downie, and D.D. Archbold. 2004. Sorbitol dehydrogenase expression and activity during apple fruit set and early development. Physiol. Plant. 121:391-398.

Nosarzewski, M. and D.D. Archbold. 2007. Tissue-specific expression of sorbitol dehydrogenase in apple fruit during early development. J. Expt. Bot. 58:1863-1872.

Nosarzewski, M., A.B. Downie, B. Wu, and D.D. Archbold. 2012. The role of sorbitol dehydrogenase in Arabidopsis thaliana. Funct. Plant Biol. 39:462-470.

Park, S.W., K.J. Song, M.Y. Kim, J.-H. Hwang, Y.U. Shin, W.-C. Kim, and W. Chung. 2002. Molecular cloning and characterization of four cDNAs encoding the isoforms of NAD-dependent sorbitol dehydrogenase from the Fuji apple. Plant Sci. 162:513-519.

Pommerrenig, B., F.S. Papini-Terzi, and N. Sauer. 2007. Differential regulation of sorbitol and sucrose loading into the phloem of Plantago major in response to salt stress. Plant Physiol. 144:1029-1038.

Ranney, T.G., N.L. Bassuk, and T.H. Whitlow. 1991. Osmotic adjustment and solute constituents in leaves and roots of waterstressed cherry (Prunus) trees. J. Amer. Soc. Hort. Sci. 116:684-688.

Roitsch, T. 1999. Source-sink regulation by sugar and stress. Curr. Opin. Plant Biol. 198-206.

Steyn, W.J., D.M. Holcroft, S.J.E. Wand, and G. Jacobs. 2004. Anthocyanin degradation in detached pome fruit with reference to preharvest red color loss and pigmentation patterns of blushed and fully red pears. J. Amer. Soc. Hort. Sci. 129:13-19.

Tari, I., G. Kiss, A.K. Deér, J. Csiszár, L. Erdei, A. Gallé, K. Gémes, F. Horváth, P. Poór, A. Szepesi, and L.M. Simon. 2010. Salicylic acid increased aldose reductase activity and sorbitol accumulation in tomato plants under salt stress. Biol. Plant. 54:677-683.

Teo, G., Y. Suzuki, S.L. Uratsu, B. Lampinen, N. Ormonde, W.K. Hu, T.M. Dejong, and A.M. Dandekar. 2006. Silencing leaf sorbitol synthesis alters long-distance partitioning and apple fruit quality. Proc. Natl. Acad. Sci. USA 103:18842-18847.

Vizzotto, G., R. Pinton, Z. Varanini, and G. Costa. 1996. Sucrose accumulation in developing peach fruit. Physiol. Plant. 96:225-230.
Wand, S.J.E., W.J. Steyn, and K.I. Theron. 2008. Vulnerability and impact of climate change on pear production in South Africa. Acta Hort. 800:263-272.

Wang, J., Y. Ou, Z. Wu, L. Dai, and S. Liu. 2011. Effects of high temperature stress on physiological indicators, early defoliation of early-maturing pear. Southwest China J. Agr. Sci. 24:546-551.

Wang, X., Y. Xu, C. Peng, R. Fan, and X. Gao. 2009. Ubiquitous distribution and different subcellular localization of sorbitol dehydrogenase in fruit and leaf of apple. J. Expt. Bot. 60:1025-1034.

Wang, Z. and G.W. Stutte. 1992. The role of carbohydrates in active osmotic adjustment in apple under water stress. J. Amer. Soc. Hort. Sci. 117:816-823.

Watari, J., Y. Kobae, S. Yamaki, K. Yamada, K. Toyofuku, T. Tabuchi, and K. Shiratake. 2004. Identification of sorbitol transporters expressed in the phloem of apple source leaves. Plant Cell Physiol. 45:1032-1041.

Wu, B., S. Li, M. Nosarzewski, and D.D. Archbold. 2010. Sorbitol dehydrogenase gene expression and enzyme activity in apple: Tissue specificity during bud development and response to rootstock vigor and growth manipulation. J. Amer. Soc. Hort. Sci. 135: 379-387.

Wu, J., Z. Wang, Z. Shi, S. Zhang, R. Ming, S. Zhu, M.A. Khan, S. Tao, S.S. Korban, H. Wang, N.J. Chen, T. Nishio, X. Xu, L. Cong, K. Qi, X. Huang, Y. Wang, X. Zhao, J. Wu, C. Deng, C. Gou, W. Zhou, H. Yin, G. Qin, Y. Sha, Y. Tao, H. Chen, Y. Yang, Y. Song, D. Zhan, J. Wang, L. Li, M. Dai, C. Gu, Y. Wang, D. Shi, X. Wang, H. Zhang, L. Zeng, D. Zheng, C. Wang, M. Chen, G. Wang, L. Xie, V. Sovero, S. Sha, W. Huang, S. Zhang, M. Zhang, J. Sun, L. Xu, Y. Li, X. Liu, Q. Li, J. Shen, J. Wang, R.E. Paull, J.L. Bennetzen, J. Wang, and S. Zhang. 2013. The genome of the pear (Pyrus bretschneideri rehd.). Genome Res. 23:396-408.

Yamaguchi, H., Y. Kanayama, and S. Yamaki. 1994. Purification and properties of NAD-dependent sorbitol dehydrogenase from apple fruit. Plant Cell Physiol. 35:887-892.

Yamaki, S. 1986. Roles of four sorbitol related enzymes and invertase in the seasonal alteration of sugar metabolism in apple tissue. J. Amer. Soc. Hort. Sci. 111:134-137.

Yao, G., S. Zhang, Y. Cao, J. Liu, J. Wu, J. Yuan, H. Zhang, and C. Xiao. 2010. Characteristics of components and contents of soluble sugars in pear fruits from different species. Scientia Agricultura Sinica 43:4229-4237.

Yu, B., D. Zhang, C. Huang, M. Qian, X. Zheng, Y. Teng, J. Su, and Q. Shu. 2012. Isolation of anthocyanin biosynthetic genes in red Chinese sand pear (Pyrus pyrifolia Nakai) and their expression as affected by organ/tissue, cultivar, bagging and fruit side. Scientia Hort. 136:29-37.

Zhang, D., B. Yu, J. Bai, M. Qian, Q. Shu, J. Su, and Y. Teng. 2012. Effects of high temperatures on UV-B/visible irradiation induced postharvest anthocyanin accumulation in 'Yunhongli No. 1' (Pyrus pyrifolia Nakai) pears. Scientia Hort. 134:53-59.

Zhou, R., L. Cheng, and A.M. Dandekar. 2006. Down-regulation of sorbitol dehydrogenase and up-regulation of sucrose synthase in shoot tips of the transgenic apple trees with decreased sorbitol synthesis. J. Expt. Bot. 57:3647-3657. 